\title{
DIREITO PESSOAL/GRUPAL À IMAGEM DOS(AS) NEGROS(AS) NA MÍDIA.
}

\author{
Tese de Doutorado \\ Orientador: Professor Doutor Dennis de Oliveira \\ Faculdade de Direito da Universidade de São Paulo. \\ São Paulo \\ 2014
}




\section{RESUMO}

Num mundo de difusão de imagens, por meios eletrônicos ou gráficos, onde conceitos, mensagens (publicidade comercial, estatal e política) e acontecimentos (por exemplo, no jornalismo) são mostrados, o direito humano à imagem é colocado à prova, pois detentores do direito reclamam do seu uso indevido. Para o Direito, algumas questões mostram-se relevantes, à medida que se busca a tutela do direito à imagem. $\mathrm{O}$ que é a imagem de uma pessoa? O que é imagem retrato e imagem atributo? Existe uma representação de grupo, imagem do grupo? Um determinado grupo pode reclamar direito à imagem? Quais as características de tal direito? Se imagens divulgadas (ex: imagens transmitidas pelas ondas eletromagnéticas) informam características fenotípicas de raça e cor, há uma imagem retrato das pessoas da cor/raça negra? Como os negros (as) querem ser representados na mídia? A pesquisa empírica mostra que as pessoas querem ser representadas na mídia com respeito. Tal postura comporta uma compreensão das pessoas como seres únicos, com suas próprias características.

Palavras chave: direito à imagem, imagem retrato, imagem atributo, direito à liberdade de expressão, direito ao acesso à informação, direito grupal à imagem, direito coletivo de imagem, raça, cor, identidade, esfera pública, estereótipo, preconceito, discriminação, mídia. 


\begin{abstract}
In a world broadcast images, electronically or graphs, where concepts, messages (commercial advertising, political and state) and events (eg, journalism) are shown, the human right to the image is put to the test, as holders of rights complain about its misuse. To the Right, some questions show up relevant, as it seeks the protection of the right to the image. What is the image of a person? What is portrait image and image attribute? There is a group representation, group picture? A particular group can claim any rights to the image? What are the characteristics of such a right? If images released (eg images transmitted by electromagnetic waves) inform phenotypic characteristics of race and color, there is a portrait of people of color / black race image? How blacks want to be represented in the media? Empirical research shows that people want to be represented in the media with respect. This attitude involves an understanding of people as unique individuals with their own characteristics.
\end{abstract}

Keywords: right to the image, image portrait, image attribute, right to freedom of expression, right to access to information, right to the image group, collective image rights, race, color, sameness, public sphere, stereotyping, prejudice, discrimination, media. 


\title{
Introdução
}

\section{A questão do preconceito de raça e cor na Constituição}

No preâmbulo da Constituição da República Federativa do Brasil $^{1}$ (CRFB), vigente desde 1988, consta que os representantes do povo brasileiro reuniram-se em Assembléia Nacional Constituinte para instituir um Estado Democrático, destinado a assegurar valores supremos (direitos humanos e justiça) de uma sociedade fraterna, pluralista e sem preconceitos (grifos da autora):

\begin{abstract}
Preâmbulo
Nós, representantes do povo brasileiro, reunidos em Assembléia Nacional Constituinte para instituir um Estado Democrático, destinado a assegurar o exercício dos direitos sociais e individuais, a liberdade, a segurança, o bem-estar, o desenvolvimento, a igualdade e a justiça como valores supremos de uma sociedade fraterna, pluralista e sem preconceitos, fundada na harmonia social e comprometida, na ordem interna e internacional, com a solução pacífica das controvérsias, promulgamos, sob a proteção de Deus, a seguinte CONSTITUIÇÃO DA REPÚBLICA FEDERATIVA DO BRASIL.
\end{abstract}

O Título I, do referido documento, falando dos princípios fundamentais da República Federativa do Brasil, no seu artigo terceiro, faz referências a tipos de preconceitos:

Art. $3^{\circ}$ Constituem objetivos fundamentais da República Federativa do Brasil:

I - Construir uma sociedade livre, justa e solidária;

II- garantir o desenvolvimento nacional;

III - erradicar a pobreza e a marginalização e reduzir as desigualdades sociais e regionais;

IV - promover o bem de todos, sem preconceitos de origem, raça, sexo, cor, idade e quaisquer outras formas de discriminação.

Logo, consta no inciso IV do artigo $3^{\circ}$ da Constituição acima que preconceitos de raça e cor são não-desejáveis, pois a promoção do bem de todos, como objetivo fundamental da República Federativa do Brasil, não comporta preconceitos de origem, raça, sexo, cor, idade e quaisquer outras formas de discriminação. Patente é tal questão,

${ }^{1}$ CONSTITUIÇÃo DA REPÚBLICA FEDERATIVA DO BRASIL. São Paulo: Saraiva, 2007. 
que praticar, induzir ou incitar preconceitos de raça e cor constituem crime, conforme consta na lei 7.716/89, alterada pela lei 9.459/97, artigo 20 :

Art. 20. Praticar, induzir ou incitar a discriminação ou preconceito de raça, cor, etnia, religião ou procedência nacional. (Redação dada pela Lei no ${ }^{\circ} 9.459$, de 15/05/97)

Pena: reclusão de um a três anos e multa. ${ }^{2}$

A presente pesquisa preocupa-se com o direito pessoal e grupal à imagem dos negros(as), grupo historicamente vulnerável, e, reconhecida a importância do objetivo constitucional de promoção do bem de todos, sem preconceitos de raça e cor, o trabalho busca uma aplicação dos conceitos, dedicando-se a uma pesquisa qualitativa a fim de inferir a presença de preconceito em relação a pessoas de cor ou raça negra nas obras audiovisuais, representadas na mídia.

O trabalho está dividido em três partes. A primeira parte do trabalho trata dos aspectos jurídicos do direito pessoal à imagem, que vai colidir com outros direitos; a segunda parte trata dos aspectos jurídicos do direito grupal com aplicação no direito grupal à imagem dos negros(as); e a terceira parte, após algumas reflexões sobre a esfera pública e privada, e a mídia, dedica-se a uma pesquisa qualitativa, a fim de responder a algumas questões tais como "Pessoas de cor ou raça negra são alvos de algum preconceito?"; "Você viu alguma imagem ou obra audiovisual na mídia que induzisse ao preconceito em relação a pessoas de cor ou raça negra?"; "Você está satisfeito com as imagens ou obras audiovisuais que vê representando pessoas da sua raça ou cor na mídia?" e "Como você gostaria que pessoas da sua raça ou cor fossem representadas na mídia?”, com objetivo de levantar indícios para o respeitoso uso da esfera pública, no que tange à imagem dos negros(as).

\footnotetext{
${ }^{2}$ BRASIL - LEI 7.716/89, Define os crimes resultantes de preconceito de raça ou de cor, disponível na internet,endereço www.planalto.gov.br/CCIVIL/Leis/L7716.htm, acesso em 21-10-2010.
} 


\section{Conclusões}

$\mathrm{O}$ direito pessoal à imagem pode ser tutelado tanto pelo direito Público como pelo Direito Privado. Como direito fundamental, sua expressão está no artigos $5^{\circ}$, incisos V, X, XXVII, XXVIII, da Constituição da República Federativa do Brasil. Sendo direito da personalidade, o direito à imagem encontra amparo explícito no artigo 20 da lei 10.406, de 10-01-1002, Código Civil. O direito pessoal à imagem deve seguir os preceitos acima citados, para quaisquer indivíduos, independente de cor ou raça, em razão do direito à igualdade. Quanto a previsão de desrespeito à igualdade racial, cometido na expressão de idéias, as quais podem conter imagens, contra grupos de raça ou cor, temos a lei 7.716/89, a qual define os crimes resultantes de preconceito de raça ou de cor.

A doutrina aponta para dois aspectos da imagem da pessoa, aspecto retrato e aspecto atributo, logo, fala-se de imagem-retrato e imagem-atributo, a primeira representando as características fisionômicas, fenotípicas, físicas; a segunda representando características relacionadas a qualidades (por exemplo, rebeldia, sensualidade, agressividade) da pessoa ${ }^{3}$. Há confluência entre imagem-atributo e reputação, considerando-a como a consideração que a sociedade tem da pessoa, pois referem-se a características sociais da pessoa, a visão da sociedade sobre a pessoa. Quanto à honra, a imagem-atributo diferencia-se da honra por grau de valoração axiológica. A imagem-atributo varia: é neutra, negativa ou positiva; a honra refere-se aos aspectos subjetivos positivos da pessoa. Nesse sentido, consideramos a honra subjetiva. A honra pode ser subjetiva ou objetiva: "A honra subjetiva pode ser sintetizada no sentimento de auto-estima do indivíduo, vale dizer, o sentimento que possui a respeito de si próprio, de seus atributos físicos, morais e intelectuais. A honra objetiva parte do parâmetro do conceito social que o indivíduo possui." Aceitando tal

\footnotetext{
${ }^{3}$ Ver TAVARES, André Ramos. Curso de Direito Constitucional. Saraiva: São Paulo, 2010, p. 686.

${ }^{4}$ ARAÚJO, Luiz Alberto David e Nunes Júnior, Vidal Serrano. Curso de Direito Constitucional. São Paulo: Editora Saraiva, 2010, p. 176.
} 
divisão para honra, a honra objetiva, a reputação, e a imagem-atributo possuem confluência quanto aos seus significados.

Os direitos à liberdade de expressão e ao acesso à informação são mencionados em documentos, como a Declaração Universal dos Direitos Humanos de 1948, artigo XIX, onde são direitos humanos a liberdade de expressão, a qual inclui a liberdade de procurar e receber informações; tais direitos constam também na Convenção Americana de Direitos Humanos, (Pacto de San José da Costa Rica). Conforme artigo 13, inciso 1. Seguindo o documento UNESCO - REPORTS AND PAPERS ON MASS COMMUniCATION. FISHER, Desmond. The Right to Communicate: A Status Report, $n^{\circ}$ 94. Rights and Freedons, o um direito geral a comunicar-se inclui: 1. O direito de falar; 2. O direito de ser ouvido; 3. O direito à resposta; 4. O direito a produzir resposta; 5. O direito de ouvir; 6. O direito de ver; 7. O direito de ser visto; 8 . O direito de expressar-se na escrita ou na imprensa; 9. O direito de expressar-se numa forma de arte; 10. O direito de ser seletivo. O direito a informar, como forma de expressão, é utilizado pelos jornalistas no seu dia a dia profissional, sendo que, segundo Marcondes, no início do jornalismo (1789-1850), os jornais eram escritos com fins pedagógicos e de formação política.

Os direitos humanos são antinômicos, ou seja, o exercício de um direito humano por dada pessoa encontra limites no exercício de direito(s) humano(s) de outra(s) pessoa(s). A Constituição da República Federativa do Brasil, artigo 5º inciso XIV fala de um direito ao acesso à informação (XIV - é assegurado a todos o acesso à informação e resguardado o sigilo da fonte, quando necessário ao exercício profissional). Os incisos X, XII, XIV, XXXIII, LX, do artigo $5^{\circ}$ da Constituição da República do Brasil defendem a vida privada, a intimidade, o sigilo e o segredo, direitos que limitam o direito ao acesso à informação. A segurança nacional limita os direitos ao sigilo de correspondência, de comunicação telegráfica e telefônica, diz-nos o artigo 136, parágrafo $1^{\circ}$, inciso I da Constituição da República Federativa do Brasil.

Quanto ao direito ao acesso à informação, reza a lei 12.527/2011, artigo 24, a qual regula o acesso a informações previsto no inciso XXXIII do art. $5^{\circ}$, no inciso II do 
$\S 3^{\circ}$ do art. 37 e no $\S 2^{\circ}$ do art. 216 da Constituição Federal; que a informação em poder dos órgãos e entidades públicas pode ser classificada como ultrassecreta, secreta e reservada, desta forma, em função do tipo de informação pública, há limites ao acesso à informação. O tratamento das informações pessoais deve ser feito com respeito à intimidade, vida privada, honra e imagem das pessoas, nos termos do artigo 31 da referida lei. A liberdade de expressão encontra limites nos direitos á privacidade, honra e na imagem. Divulgação de segredo pode ser crime, de acordo com a lei 2.848 , de 7 12-1940 - Código Penal, artigo 53. A imagem divulgada, não pode ferir o direito à honra. E, de acordo com o artigo 20 da lei

10.406, de 10-01-1002, Código Civil, salvo se autorizadas, ou se necessárias à administração da justiça ou à manutenção da ordem pública, a divulgação de escritos, a transmissão da palavra, ou a publicação, a exposição ou a utilização da imagem de uma pessoa poderão ser proibidas, a seu requerimento e sem prejuízo da indenização que couber, se lhe atingirem a honra, a boa fama ou a respeitabilidade, ou se se destinarem a fins comerciais. Assim, a divulgação da imagem precisa de autorização, e podem ser proibidas a seu requerimento se lhe atingirem a honra, boa fama, ou se se destinarem a fins comerciais.

O presente estudo considera a expressão "grupo de pessoas" em sentido amplo e geral, englobando grupos sociais e agregados sociais. Um dado grupo de pessoas pode ter direitos específicos para seu grupo, como por exemplo, o grupo da terceira idade e o grupo de crianças e adolescentes, sem que esses grupos tenham estratificação social, determinando hierarquia, mesmo de natureza informal. Chamamos de direitos grupais no presente estudo os direitos de grupos de pessoas.

A lei $\mathrm{n}^{\circ} 8.078$, de 11 de setembro de 1990 , a qual dispõe sobre a proteção do consumidor, oferece a seguinte divisão para direitos grupais, para a referida lei: 1) interesses ou direitos difusos; 2) interesses ou direitos coletivos; 3) interesses ou direitos individuais homogêneos. Os interesses ou direitos difusos, assim entendidos, os transindividuais, de natureza indivisível, de que sejam titulares pessoas indeterminadas e ligadas por circunstâncias de fato; os interesses ou direitos coletivos, assim entendidos, para efeitos deste código, os transindividuais, de natureza indivisível de que seja titular grupo, categoria ou classe de pessoas ligadas entre si ou com a parte contrária por uma relação jurídica base; os interesses ou direitos individuais 
homogêneos, assim entendidos os decorrentes de origem comum. O Ministério Público é parte legítima para defender os interesses ou direitos elencados, bem como a associação que, concomitantemente: a) esteja constituída há pelo menos 1 (um) ano nos termos da lei civil; b) inclua, entre suas finalidades institucionais, a proteção ao meio ambiente, ao consumidor, à ordem econômica, à livre concorrência ou ao patrimônio artístico, estético, histórico, turístico e paisagístico.

Quanto ao direito grupal à imagem, os autores Baptista e Valle e a Portaria n. 177 da FUNAI, ao analisar o direito coletivo de imagem indígena, caracterizam um direito grupal à imagem e ao enfatizar no referido direito os aspectos culturais e sociais da imagem, aproximam-na da imagem-atributo, que por definição, representa as características sociais e as qualidades da pessoa. Pesquisa do IBGE mostrou que, para São Paulo, 59,8\% dos entrevistados definem cor ou raça por traços físicos, enquanto $83.3 \%$ definem cor e raça pela cor da pele ${ }^{5}$, assim, a pesquisa mostra que cor de pele é um item pelo qual as pessoas definem raça. Perguntamos, então, se a imagem pode conter marcadores fenotípicos raciais. A evidência aponta para a resposta sim, quanto a cor, pelo exemplo recolhido no site da Polícia Civil. Na página da Polícia Civil, lê-se nas legendas dos retratos falados o tópico descritivo cor. Considerando o retrato falado como exemplo de imagem, e entre outros a Polícia civil apresenta no seu site retratos falados coloridos, (inferência feita pelo escrito na legenda do referido site "OBS: A caracterização acima não é uma foto. Trata-se de uma técnica de retrato falado colorido." $\left.{ }^{\prime}\right)$, conclui-se que é possível que numa imagem haja representação de marcadores fenotípicos raciais, em outras palavras, uma dada imagem pode conter o item cor, no exemplo captado na internet, através da divulgação de uma técnica de retrato colorido, que, por definição, mostra cor. A conclusão é que a medida que a imagem mostra marcadores fenotípicos raciais, como por exemplo, cor, o direito grupal à imagem dos grupos raciais aproxima-se da imagem-retrato, recepcionando o direito grupal à imagem nas suas duas formas: retrato e atributo.

\footnotetext{
${ }^{5}$ BRASIL - IBGE - Características étnico-raciais da população - Um estudo das categorias de classificação de cor ou raça - 2008 Disponível em http://biblioteca.ibge.gov.br/visualizacao/livros/liv49891.pdf, acesso em 13-01-2014.
}

${ }^{6}$ BRASIL - Site da Polícia Civil do Estado de São Paulo. Disponível em: http://www2.policiacivil.sp.gov.br/x2016/Retrato falado/homens.php, acesso em 11-01-2014. 
Observando as esferas privada e pública da antiguidade, notamos que eram separadas, seu espaço físico era bem definido. Atualmente, com a mídia, ou meios de comunicação de massa, há um locutor nas duas esferas: a mídia está presente na esfera pública, e na esfera privada, pois freqüenta os lares, os dormitórios, os escritórios, como um falante tecendo seu monólogo. Está na esfera pública porque suas informações tornam-se comuns ao grupo de audiência, o qual pode, em conjunto, tomar decisões em função da informação, como por exemplo, comparecer à uma campanha de vacinação anunciada na mídia. Por essa razão, há responsabilidade na transmissão de informações.

Na mídia, não há comunicação no que tange à resposta do receptor, este apenas recebe mensagens, seu direito de resposta é proporcional ao agravo e o direito de antena é devido aos partidos políticos. Dessa forma, o espectro de ondas eletromagnéticas, bem difuso, é pouco, (quase nada), utilizado pela população para comunicação, e sim utilizado pelos concessionários, permissionários ou autorizados, para emissão de suas mensagens. O "público" usa bem pouco o espaço público, a esfera pública, na sua dimensão "mídia". O presente trabalho é favorável a um direito de antena para determinados grupos de interesse social, como aqueles desfavorecidos na própria mídia, pela invisibilidade e pelo uso de estereótipos. Sobre o direito de antena, este deveria ampliar-se no Brasil. Atualmente no Brasil tal direito é garantido para partidos políticos, enquanto em Portugal o direito de antena cabe a outras entidades. Para Fiorillo, o direito de antena é o direito de captar e transmitir ondas eletromagnéticas, sendo que a utilização do espectro eletromagnético significa a utilização de um bem ambiental ${ }^{7}$.

Buscando uma aplicação dos temas levantados, foi feita uma pesquisa de campo com foco no grupo dos negros (as), a fim de verificar se a imagem do referido grupo está bem representada na mídia, e como o grupo gostaria de se ver representado. Alguns dados gerais da amostra são os seguintes: Quanto ao estado civil: Casados(as) 44\%,Viúvos(as) 5\%, Divorciados(as) 11\% e Solteiros(as) 40\%; a idade média é de 45

\footnotetext{
${ }^{7}$ FIORILLO, Celso Antônio Pacheco. Curso de Direito Ambiental. 10a edição. São Paulo: Saraiva, 2009, p. 271.
} 
anos; quanto ao sexo: $\quad 41 \%$ dos respondentes é do sexo masculino, enquanto $59 \%$ dos respondentes é do sexo feminino. A renda média do grupo em julho de 2013 foi de $\mathrm{R} \$$ 2345,80. Dos respondentes, têm $1^{\circ}$ grau incompleto: $16 \% ; 1^{\circ}$ grau completo: $13 \%$ : $2^{\circ}$ grau completo: $28 \% ; 3^{\circ}$ grau completo $37 \%$; e sem resposta: $6 \%$.

A raça ou cor predominante da amostra é a negra, com 75,9\% de autodeclarados nessa categoria, $19,28 \%$ dos respondentes se declarou da cor ou raça branca; $1,2 \%$ se declarou amarela; $3,62 \%$ se declarou indígena.

Perguntou-se às pessoas "Para você, o que é preconceito?"; as respostas corresponderam a idéias preconcebidas sobre determinado grupo. Outras respostas entenderam o preconceito em termos de comportamento, ou seja, a manifestação do mesmo, utilizando para tanto, termos como discriminação.

Buscando avaliar se o grupo de negros (as) sofre preconceito, foi feita a seguinte pergunta: “9. Pessoas de cor ou raça negra são alvos de algum preconceito? ( ) sim ( ) não"; $87 \%$ dos respondentes da amostra disse que pessoas de cor ou raça negra são alvos de algum preconceito, confirmando assim, as queixas do grupo.

A pergunta seguinte, "10. Você foi alvo de algum preconceito? ( ) sim ( ) não" obteve o seguinte resultado: $52 \%$ da amostra relatou ter sofrido pessoalmente preconceito.

Perguntou-se: “11. Esse preconceito impediu de exercer algum direito? ( )sim ( ) não", que obteve como resposta: $25 \%$ sim; $60 \%$ não; e $15 \%$ não respondeu. Observamos o número elevado de pessoas que alegam ter tido impedimento de exercer direito em função do preconceito.

A amostra revelou que as pessoas consideram que o termo mídia se refere à TV, rádio, revistas, jornais, idéias concernentes com as de Marilena Chauí.

Quanto à pergunta "13- Você viu alguma imagem ou obra audiovisual na mídia que induzisse ao preconceito em relação a pessoas de cor ou raça negra? ( ) sim ( ) não”, 
ela obteve como respostas: 51,81\% sim, 42,17 não e 6,02\% não respondeu. Esses são os resultados da amostra geral. Dividindo o grupo em subgrupos por raça ou cor, temos os seguintes resultados: dos 63 respondentes que se declararam da cor ou raça negra, $50,79 \%$ responderam sim, viram alguma imagem ou obra audiovisual na mídia que induzisse ao preconceito em relação a pessoas de cor ou raça negra, 41,26\% responderam não, e 7,93\% não responderam; dos 16 respondentes que se declararam da cor ou raça branca, responderam Sim - 56,25\% e Não - 43,75\%. Comparando os dois grupos, o de cor ou raça negra e o de cor ou raça branca suas opiniões não diferem muito quanto à questão, nos grupos, mais de 50\% dos membros viram alguma imagem ou obra audiovisual na mídia que induzisse ao preconceito em relação a pessoas de cor ou raça negra.

Continuando na pergunta 13 do questionário, segundo questionamento "Quem veiculou?" treze respondentes citam de maneira genérica a TV, e dez respondentes citam como veículo especificamente a "TV Globo". A pergunta é feita no passado, "quem veiculou". e não localiza quanto tempo passado: Tempo mais recente ou tempo mais longínquo, mas três respostas dão indicação do tempo em que ocorre/ocorreu, são as seguintes: "36- Diariamente na rede globo"; "61- Por exemplo na novela escrava Isaura, onde os negros eram totalmente excluídos (TV rede globo)” ;“93- O programa da Xuxa não tem pessoas negras (Na TV Globo)”.

Quanto à reação dos respondentes, por aqueles que dizem ter assistido na mídia cena que induzisse ao preconceito, encontramos respostas como: "01- Gostaria de ter um cargo que acabasse com essa brincadeira"; "03- Ficar indignada"; "04- Tirar imediatamente do canal de TV"; "05- Mudar de canal”; "06- Desligar a TV"; "07Mudar de canal'; "08- Fico chocada"; "09- Fico indignada"; "10- Fico insatisfeita"; “11- Mudo de canal’; “12- Ficar indignada por não poder mudar esta situação". Sentimentos relacionados à indignação, revolta, tristeza, predominam, como reações ao assistir a uma cena na mídia que induza ao preconceito. Alguns respondentes disseram que mudam de canal, ao assistirem a tal cena.

A pergunta "15. Você está satisfeito com as imagens ou obras audiovisuais que vê representando pessoas da sua raça ou cor na mídia?”, obteve dos que se declararam 
da raça ou cor negra, 28,57\% responderam sim; 61,90\% responderam não; 7,94\% não responderam, e uma pessoa, representando 1,59\%, respondeu "sim e não" à questão 15 . Existe a falta de representatividade, a invisibilidade, e a baixa representatividade dos homens e mulheres negras. Dos que se declararam da raça ou cor branca, 43,75\% respondeu "sim"; 43,75\% respondeu "não"; 12,50\% não respondeu à questão 15. Logo, dos declarados de raça ou cor negra, $61,90 \%$ está insatisfeito com as imagens ou obras audiovisuais que vê representando pessoas da sua raça ou cor na mídia, enquanto, dos declarados de raça ou cor branca, $43,75 \%$ está insatisfeito com as imagens ou obras audiovisuais que vê representando pessoas da sua raça ou cor na mídia .Perguntados como gostariam que pessoas da sua raça ou cor fossem representadas na mídia, valores como igualdade, dignidade e respeito se destacaram. 


\section{Recomendações:}

1. Direito de antena para grupos desfavorecidos, sem voz, grupos pouco representados (invisibilidade) ou representados de formas indesejadas pelo grupo. O que é ter voz, ter o direito de antena? É, por exemplo, expressar a opinião sobre o humor: gostou ou não gostou. O humor é gratificante numa platéia de iguais, onde todos podem se expressar. Só há humor onde há igualdade, fora isso é afronta, é bullying. A esfera pública é o lócus onde as pessoas se encontram e trocam idéias. $\mathrm{O}$ espectro das ondas eletromagnéticas é um bem difuso, bem de uso comum do povo, pelas quais idéias podem ser divulgadas a grande massa de pessoas. O poder da TV em chamar e prender a atenção é notório, bem como sua aceitação em vários tipos de recinto: a TV está nos lares, nos dormitórios, nas salas de espera, nos bares, nos quartos de hotel, nos restaurantes, divulgando informações, tendências, propaganda, enfim, divulgando uma programação. Tal programação não é aleatória, toda captação de imagem envolve um certo ponto de vista, designado por um diretor ou escolhido pelo cinegrafista. Posteriormente, as imagens captadas são editadas, ou seja, do material "bruto", são escolhidas cenas, e a estas são acrescidas música, locução, letreiros, efeitos especiais. A TV não mostra "a realidade", mostra aspectos do mundo conforme um ponto de vista. A obra audiovisual exposta na TV é uma edição, uma escolha de imagens e sons feita por uma ou mais pessoas, que seguem um roteiro. Uma edição é uma das maneiras de contar determinada estória. Um acontecimento pode ter tantas versões quantos observadores houver, tantas cenas quantos cinegrafistas houver, tantas edições quantos editores houver. É de interesse social que as informações, os vários pontos de vista da realidade sejam mostrados na esfera pública, em razão do juízo crítico a ser formado. A esfera pública é lócus da esfera pública política, e ela é essencial para a democracia, interesse e direito difuso.

2. Um instituto público de pesquisas e arquivamento da produção midiática, como preservação do patrimônio cultural e das evidências de prática abusiva.

3. Lei de Cotas para negros (as) no mercado midiático e da moda, por eventos em dado período, não necessariamente cotas por estilista, por novela ou por propaganda. 
As cotas devem corresponder a número de aparições no setor/mercado, mas não só isso, também a qualidade da representatividade deve ser incluída numa lei de cotas, por exemplo, papéis de protagonistas para negros(as). As justificativas são duas: Primeiro, tais setores são divulgadores de idéias na esfera pública. Eles têm penetração na esfera pública (audiência) dos eventos como um todo, não de um estilista, num dado desfile, por isso, as cotas devem ser consideradas por setor. Segundo, a lei não prevê todas manifestações de preconceito de raça e cor, por si, discriminatórias, como o conjunto de pessoas jurídicas que compõem o mercado da moda ou midiático, onde, ao manifestarem a mesma preferência por tipo racial, constroem uma barreira para o ingresso de negros(as) no referido mercado. É uma questão de direito ao trabalho, pois há, dessa forma, discriminação para entrada nesse mercado de trabalho, e também um direito de participação na esfera pública (visibilidade), é direito à comunicação.

4. Educação. Nas escolas e na esfera pública, o que implica na mídia, campanhas educativas para valorização dos direitos humanos e da igualdade racial.

5. Instituto Público de Pesquisas de Opinião Pública, vinculado ao Ministério Público, com objetivo de inferir por amostragem, a satisfação do público quanto ao exercício dos interesses e direitos difusos.

6. O que você vê em um indivíduo, não classifique., não julgue, as aparências enganam. Cuidado com rótulos e estereótipos. Devemos optar pelo diálogo e o respeito à identidade.

7. Agradecer a todos que lutam pela causa da igualdade racial, agradecer àqueles que, mesmo não sendo vítimas do preconceito/discriminação racial, se solidarizam com a causa. 
Bibliografia 


\section{BIBLIOGRAFIA CONSULTADA}

ADORNO, Theodor W. e HORKHEIMER, Max. Dialética do Esclarecimento. Rio de Janeiro: Zahar, 1985.

AFFORNALLI, Maria Cecília Naréssi Munhoz. Direito à própria imagem. Curitiba: Juruá Editora, 2008.

ALEXY, Robert. Teoria dos Direitos Fundamentais. São Paulo: Malheiros Editores Ltda., 2011.

AMARAL Jr., Alberto do. Comércio Internacional e a Proteção do Meio Ambiente. São Paulo: Atlas, 2011.

ARANHA, Márcio Iorio (org.). Coletânea de Normas e Julgados de Telecomunicações e Glossário Brasileiro de Direito das Telecomunicações. São Paulo: Quartier Latin, 2006.

ARAÚJO, Luiz Alberto David e Nunes Júnior, Vidal Serrano. Curso de Direito Constitucional. São Paulo: Editora Saraiva, 2010.

ARAÚJO, Bráulio Santos Rabelo. A construção da esfera pública no Brasil a partir da Constituição de 1988. Tese de doutorado apresentada ao Departamento de Direito Econômico, Financeiro e Tributário da Faculdade de Direito da Universidade de São Paulo, 2011.

ARAÚJO, Luiz Alberto David Araujo. A proteção constitucional da própria imagem: pessoa física, pessoa jurídica e produto. Belo Horizonte: Del Rey, 1996.

ARENDT, Hannah. A condição humana. Rio de Janeiro: Forense Universitária, 2010 .

BARTHES, Roland. Elementos de Semiologia. São Paulo: Cultrix. 
BATISTA, Leandro Leonardo \& LEITE, Francisco (orgs.). O negro nos espaços publicitários brasileiros - perspectivas contemporâneas em diálogo. São Paulo: Escola de Comunicações e Artes/USP:Coordenadoria dos Assuntos da População Negra, 2011.

BELTRÃO, Sílvio Romero. Direitos da personalidade: de acordo com o Novo Código Civil. São Paulo: Atlas, 2005.

BITTAR, Eduardo C. B. \& ALMEIDA, Guilherme Assis de. Minicódigo de direitos humanos. Associação Nacional de Direitos Humanos (ANDHEP). Secretaria Especial de Direitos Humanos da Presidência da República (SEDH). Brasília: Teixeira Gráfica e Editora, 2010.

BITTAR, Carlos Alberto. Os Direitos da Personalidade. Rio de Janeiro: Forense Universitária, 1999.

BOBBIO, Norberto. A era dos direitos. Rio de Janeiro: Campus: Elsevier, 2004.

BONAVIDES, Paulo. Curso de Direito Constitucional. São Paulo: Malheiros Editores, 2007, 20ª edição.

BORDIEU, Pierre. Sobre a televisão. Rio de Janeiro: Jorge Zahar Ed., 1997.

BUlOS, Uadi Lammêgo. Curso de Direito Constitucional. São Paulo: Saraiva, 2011.

CARONE, Iray e BENTO, Maria Aparecida Silva (organizadoras). Psicologia Social do racismo - Estudos sobre branquitude e branqueamento no Brasil. Petrópolis: Vozes, 2002.

CARVALHO et al. Direito da Comunicação Social - $O$ regime jurídico da Comunicação Social em Portugal. Cruz Quebrada: Casa das Letras, 2005, $2^{\text {a }}$ edição, revista e comentada. 
CHAUI, Marilena. Simulacro e poder: uma análise da mídia. São Paulo: Editora Fundação Perseu Abramo, 2006.

COMIS, MARIA ; NOTO, ANA . Reasons for not using ecstasy: a qualitative study of non-users, ex-light users and ex-moderate users. BMC Public Health (Online) , v. 12, p. 353, 2012.

COLOMA, Aurelia Maria Romero. Derecho a La Informacion y Libertad de Expression. Barcelona: Bosch, Casa Editorial S.A., 1984.

COMPARATO, Fábio Konder. A afirmação histórica dos direitos humanos. São Paulo: Saraiva, 2005.

CONSTITUIÇÃO DA REPÚBLICA FEDERATIVA DO BRASIL. São Paulo: Saraiva, 2011.

CUPIS, Adriano. Os direitos da personalidade. São Paulo: Quorum, 2008.

DALLARI, Dalmo de Abreu . Direitos humanos e cidadania. São Paulo: Moderna, 2002.

DALLARI, Dalmo de Abreu . Que são direitos da pessoa? 10. ed. São Paulo: Brasiliense, 1994.

D’ANGELO, Élcio. Estatuto da igualdade racial comentado. Lei no 12.288, de 20 de julho de 2010. São Paulo: Edijur, 2010.

DIMOULIS, Dimitri e MARTINS, Leonardo. Teoria Geral dos Direitos Fundamentais. São Paulo: Editora Revista dos Tribunais, 2007.

DORETTO, Fernanda Orsi Baltrunas. Direito à imagem. Dissertação de Mestrado apresentada à Faculdade de Direito da Universidade de São Paulo, 2003. 
FACHIN, Zulmar Antonio. A proteção jurídica da imagem. São Paulo: Celso Bastos Editor: Instituto Brasileiro de Direito Constitucional, 1999.

FANON, Frantz. Pele Negra Máscaras Brancas. Salvador: EDUFBA, 2008.

FLUSSER, Vilém. O universo das imagens técnicas. São Paulo: Annablume, 2008.

FERNANDES NETO, Guilherme. Direito da Comunicação Social. São Paulo: Editora Revista dos Tribunais, 2004.

FILHO, Ciro Marcondes. Comunicação e Jornalismo. A Saga dos cães perdidos. São Paulo: Hacker Editores, 2000.

GARCIA, Enéas Costa. O direito geral da personalidade no sistema jurídico brasileiro. Tese de doutorado. Faculdade de Direito da Universidade de São Paulo,2005.

GODOY, Claudio Luiz Bueno. A liberdade de imprensa e os direitos de personalidade. São Paulo: Atlas, 2001.

GUIMARÃES, Antonio Sérgio Alfredo. Preconceito racial - Modos, temas e tempos. São Paulo: Cortez, 2008.

GUIMARÃES, Antonio Sérgio Alfredo. Racismo e Anti-Racismo no Brasil. São Paulo: Ed. 34, 1999.

HABERMAS, Jürgen. Mudança estrutural da esfera pública: investigações quanto a uma categoria da sociedade burguesa. Rio de Janeiro: Tempo Brasileiro, 2003.

INSTITUTO AMMA PSIQUE E NEGRITUDE. Psique Negritude - Os efeitos psicossociais do racismo. Imprensa Oficial do Estado de São Paulo. São Paulo, 2008. 
Legislação de direitos difusos e coletivos / obra coletiva de autoria da Editora Saraiva com a colaboração de Antonio Luiz de Toledo Pinto, Márcia Cristina Vaz dos Santos, Windt e Livia Céspedas - 6. ed. Reform - São Paulo: Saraiva, 2010. - (Coleção Saraiva de Legislação).

Legislação básica sobre direitos humanos. Compilação organizada para a LTr Editora por HB Textos. São Paulo: LTr, 1999.

JABUR, Gilberto Haddad. Limitações ao Direito à Própria Imagem no Novo Código Civil. In: Questões Controvertidas no Novo Código Civil. São Paulo: Método, 2003.

JABUR, Gilberto Haddad. Liberdade de pensamento e direito à vida privada: conflitos entre direitos da personalidade. São Paulo: Editora Revista dos Tribunais, 2000.he v

KELLY, John M. Uma breve história da teoria do Direito Ocidental. São Paulo: Martins Fontes, 2010.

LENZA, Pedro. Direito Constitucional. São Paulo: Saraiva, 2010.

LIMA, Venício A. de Lima. Liberdade de Expressão x Liberdade da imprensa. Direito à comunicação e democracia. Prefácio de Fábio Konder Comparato. São Paulo: Publisher Brasil, 2012.

MAIA, Rousiley \& CASTRO, Maria Céres Pimenta Spínola (orgs.). Mídia, esfera pública e identidades coletivas. Belo Horizonte: Editora UFMG, 2006.

MARCONDES FILHO, Ciro. Comunicação e Jornalismo- a saga dos cães perdidos. São Paulo: Hacker Editores, 2000.

MAZZILLI, Hugo Nigro. Tutela dos interesses difusos e coletivos. São Paulo: Damásio de Jesus, 2007. 
MENDES, Soraia da Rosa. Esfera Pública e Direitos Fundamentais: estudos sobre a liberdade de comunicação. Passo Fundo: Instituto Superior de Filosofia Berthier, 2008.

MINISTÉRIO PÚBLICO DO ESTADO DE SÃO PAULO. Grupo de Atuação Especial de Inclusão Social - GAEIS. Termo de compromisso de ajustamento de conduta. Assinado em 20 de maio de 2009. Endereço na internet: http://WWW.mp.sp.gov.br/portal/page/portal/noticias/publicação_noticias/Fotos/tac\%2 0sp\%20fashion\%20week.pdf. Acesso em 05/11/09.

MOTES, Carlos Maluquer. Derecho de La Persona y negocio jurídico. Barcelona: Bosch, Casa Editorial, S.A., 1993.

MUNANGA, Kabengele. "Uma abordagem conceitual das noções de raça, racismo, identidade e etnia”. In: BRANDÃO, André Augusto P., (org.). Programa de educação sobre o negro na sociedade brasileira. Niterói: EDUFF, 2004.

OLIVEIRA, Dennis e PAVAN, Maria Ângela. Identificações e estratégias nas relações étnicas na telenovela "Da Cor do Pecado". REVISTA DE COMUNICAÇÃO E CULTURA. Processos mediáticos e culturais. Universidade Metodista de Piracicaba UNIMEP. Vol I, nº 1, 2006

PODESTÁ, Fábio Henrique. Interesses Difusos, Qualidade da Comunicação e Controle Judicial. São Paulo: Editora Revista dos Tribunais, 2002.

PRUDENTE, Eunice Aparecida de Jesus. "O negro na ordem jurídica brasileira". Revista da Faculdade de Direito USP, São Paulo, V. 83, 1988.

RAMOS, Silvia (org.). Mídia e racismo. Rio de Janeiro: Pallas, 2002.

REVISTA DE COMUNICAÇÃO E CULTURA. Processos mediáticos e culturais. Universidade Metodista de Piracicaba - UNIMEP. Vol. I, nº 1, 2006, 144 p. 
REVISTA USP. São Paulo: USP, n. 69, mar/mai. 2006, 208 p.

REVISTA USP. São Paulo: USP, n. 68, dez/fev. 2005/2006. 341 p.

REVISTA USP. São Paulo: USP, n. 28, dez/fev. 1995-1996. 264 p.

RODRIGUES, Diogo Moyses. O Direito Humano à Comunicação: Igualdade e Liberdade no Espaço Público Mediado por Tecnologias. Dissertação de Mestrado. Faculdade de Direito da Universidade de São Paulo, 2010.

ROVEGNO, André. Os direitos fundamentais à honra e à imagem como limite às ações de polícia judiciária no inquérito policial. Tese de Doutorado. Faculdade de Direito da Universidade de São Paulo, 2011.

SAMPAIO, José Adércio Leite. Direito à intimidade e à vida privada: uma visão jurídica da sexualidade, da família, da comunicação e informações pessoais, da vida e da morte. Belo Horizonte: Del Rey, 1998.

SANTAELlA, Lucia. Semiótica Aplicada. São Paulo: Cengage Learning, 2012.

SMANIO, Gianpaolo Poggio. Interesses Difusos e Coletivos. São Paulo: Atlas, 2006.

STROPPA, Tatiana. As Dimensões constitucionais do direito de informação e o exercício da liberdade de informação jornalística. Belo Horizonte: Fórum, 2010.

TAVARES, André Ramos. Curso de Direito Constitucional. Saraiva: São Paulo, 2010.

TAYLOR, Charles. Imaginários Sociais Modernos. Lisboa: Edições Texto \& Grafia, Ltda, 2010.

TAYLOR, Charles. Argumentos filosóficos. São Paulo: Edições Loyola, 2000. 
VAZ, Paulo Afonso Brum e SCHÄFER, Jairo Gilberto (organizadores). Curso Modular de Direito Constitucional. Santa Catarina: Editora Conceito Editorial, 2008.

VENTURI, Elton. Processo Civil Coletivo. São Paulo: Malheiros Editores Ltda., 2007.

VIEIRA, Jair Lot Vieira (supervisão editorial). LEI DE IMPRENSA: Lei $\mathbf{n}^{\mathbf{0}}$ 5.250, de 9 de setembro de 1967. - $4^{\text {a }}$ ed. rev., ampl. E atual, com a Medida Cautelar de 21.2.2008 - STF - Bauru, SP: EDIPRO, 2008. 